Article

\title{
Nickel-Oxide Based Thick-Film Gas Sensors for Volatile Organic Compound Detection
}

\author{
Sai Kiran Ayyala *(D) and James A. Covington *(D) \\ School of Engineering, University of Warwick, Coventry CV4 7AL, UK \\ * Correspondence: Sai-Kiran.Ayyala@warwick.ac.uk (S.K.A.); J.A.Covington@warwick.ac.uk (J.A.C.)
}

Citation: Ayyala, S.K.; Covington, J.A. Nickel-Oxide Based Thick-Film Gas Sensors for Volatile Organic Compound Detection. Chemosensors 2021, 9, 247. https://doi.org/ $10.3390 /$ chemosensors 9090247

Academic Editor: Ana Rovisco

Received: 15 July 2021

Accepted: 27 August 2021

Published: 3 September 2021

Publisher's Note: MDPI stays neutral with regard to jurisdictional claims in published maps and institutional affiliations.

Copyright: (C) 2021 by the authors. Licensee MDPI, Basel, Switzerland. This article is an open access article distributed under the terms and conditions of the Creative Commons Attribution (CC BY) license (https:// creativecommons.org/licenses/by/ $4.0 /)$.

\begin{abstract}
In this paper, we report on the development of a highly sensitive and humidity-tolerant metal-oxide-based volatile organic compound (VOC) sensor, capable of rapidly detecting low concentrations of VOCs. For this, we successfully fabricated two different thicknesses of nickel oxide $(\mathrm{NiO})$ sensors using a spin-coating technique and tested them with seven different common VOCs at $40 \%$ r.h. The measured film thickness of the spin-coated NiO was $\sim 5 \mu \mathrm{m}$ (S-5) and $\sim 10 \mu \mathrm{m}$ (S-10). The fastest response and recovery times for all VOCs were less than $80 \mathrm{~s}$ and $120 \mathrm{~s}$, respectively. The highest response $\left(\mathrm{R}_{\mathrm{g}} / \mathrm{R}_{\mathrm{a}}=1.5\right.$ for $5 \mathrm{ppm}$ ethanol) was observed at $350{ }^{\circ} \mathrm{C}$ for both sensors. Sensors were also tested in two different humidity conditions ( $40 \%$ and $90 \%$ r.h.). The humidity did not significantly influence the observed sensitivity of the films. Furthermore, S-10 NiO showed only a 3\% drift in the baseline resistance between the two humidity conditions, making our sensor humidity-tolerant compared to traditional $n$-type sensors. Thus, we propose thick-film $\mathrm{NiO}(10 \mu \mathrm{m})$ sensing material as an interesting alternative VOC sensor that is fast and humidity-tolerant.
\end{abstract}

Keywords: gas sensors; $\mathrm{NiO}$; metal-oxide semiconductor (MOX); thick-film sensors; volatile organic compound (VOC)

\section{Introduction}

The abundance of volatile organic compounds (VOCs) present in the air is an everincreasing worldwide problem [1]. Everyday human activity results in the emission of toxic chemicals, including VOCs, driven by the increase in global industrial processes. According to the World Health Organization (WHO), there are more than 4.2 million deaths every year as a result of air pollution, with an increasing percentage of these deaths linked to VOCs [2]. Several major environmental safety agencies, such as the National Institute of Occupational Safety and Health (NIOSH), Environmental Protection Agency (EPA), and European Agency for Safety and Health at Work (EU-OSHA), have established guidelines to limit both the indoor and outdoor exposure of humans to VOCs. These can affect individuals even at low ppm (parts per million) concentrations [3]. VOCs are very complex to detect, particularly when separating VOCs of similar chemical structures. This is particularly problematic when similar VOCs have very different exposure limits, sometimes by a factor of 1000 . Thus, the detection of VOCs, at low concentrations, remains both important and challenging.

Chemo-resistive-type gas sensors, based on metal-oxide semiconductors (MOX), are one of the most used sensing modalities for monitoring harmful VOCs. These types of sensors have several advantages, including fast response times, high sensitivity to target gases, simple design, small dimensions, portability, cost-effective fabrication, ease of use, and real-time detection [4]. One variable that can be adjusted in the sensor design is the thickness of the sensing material. Researchers have loosely defined sensors as being (a) thin-film or (b) thick-film [5,6]. The thickness of a typical 'thin film' sensor is a few hundred nanometers, while a 'thick film' is a few microns to 100 microns [7]. For thin films, the chemisorption interaction mostly takes place at the geometric surface and, to a limited 
extent, along grain boundaries. Meanwhile, for a thick-film sensor, the active surfaces are much larger, due to the porous nature of the film, and the gas interaction occurs throughout the bulk material [8]. Furthermore, thick-film gas sensors have other added advantages, including low-cost material deposition, simple construction, and good sensing properties, making them more favourable to some VOC applications [9].

Improving the sensor's performance and enhancing sensitivity has always been a challenge for MOX sensors. Even after years of significant research on MOX materials, researchers are still investigating different methods to enhance their sensitivity towards VOCs. Comparing the literature, most research has been conducted on $n$-type semiconductor materials, such as $\mathrm{SnO}_{2}, \mathrm{ZnO}$, and $\mathrm{WO}_{3}$ [10-14]. This is due to $p$-type materials generally having lower sensitivity (associated with the nature of the charge carriers) [15-17]. However, it has been proposed that the effect of humidity is lower on $p$-type MOX materials compared to $n$-type [18]. Nickel oxide is a $p$-type material that is chemically stable with a bandgap between 3.4 to $4.0 \mathrm{eV}$ depending on the deposition methods and the crystallinity, making it an interesting sensing material for chemo-resistive sensors [19]. An example of a $p$-type study with $\mathrm{NiO}$ and VOCs was carried out by Vincent et al. However, there was a substantial drift in the baseline resistance of their sensors [20]. Dirksen et al. tested a NiO thin film on formaldehyde, operating at an elevated temperature of $600^{\circ} \mathrm{C}$ [21]. H. Liu et al. deposited $\mathrm{NiO}$ using a wet chemistry method and tested it on different VOCs at a range of concentrations from 100 to $500 \mathrm{ppm}$. Unfortunately, the sensitivities for ethanol and toluene were relatively low [22].

To the best of our knowledge, $\mathrm{NiO}$ thick films have not previously been fabricated using a spin-coating technique. Therefore, in this work, we deposited $\mathrm{NiO}$ using a novel photolithography-assisted spin coating method. Though $\mathrm{NiO}$ is a widely studied material for gas sensing, there are significant gaps in the reported results for this material. Specifically, $\mathrm{NiO}$ thick films have not previously been evaluated on parameters such as humidity tolerance or the effect of different thicknesses on sensitivity or tested on a wide variety of VOCs (at high and low concentration levels). Thus, in this work, we successfully fabricated two different thicknesses $(5 \mu \mathrm{m}$ and $10 \mu \mathrm{m})$ of $\mathrm{NiO}$ thick films, produced by spin coating. In addition, we focused extensively on low-level gas detection for a variety of common VOCs. Finally, we studied the fabricated devices under two different humidity levels to evaluate the performance and baseline drift of $\mathrm{NiO}$ sensors.

\section{Materials and Methods}

The substrates used in this work were based on a ceramic tile. Gold electrodes were deposited using a screen-printing method on an alumina tile of $2 \times 2 \mathrm{~mm}$ size with a platinum heater below. Figure 1 shows a drawing of the cross section of the device used in this work. Two different thicknesses of $\mathrm{NiO}$ layers were deposited as the sensor material by photolithography-assisted spin coating (S-5 and S-10).

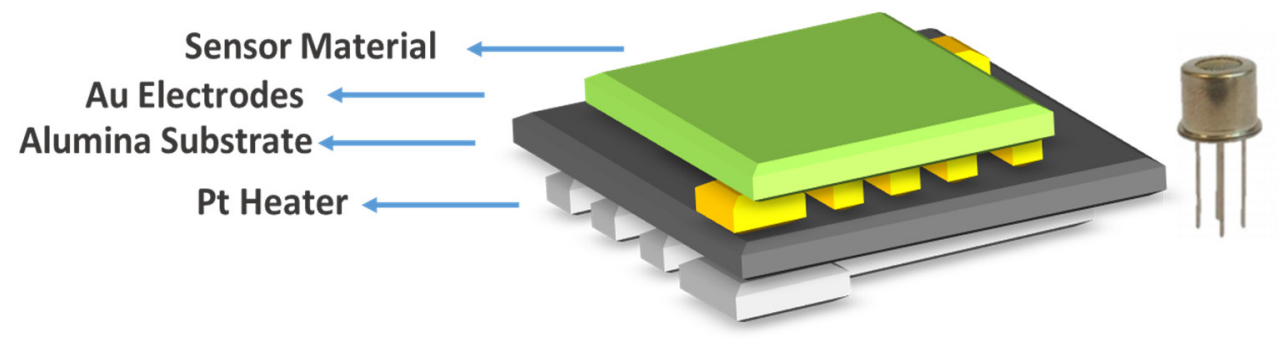

Figure 1. Sensor schematic of a spin-coated $\mathrm{NiO}$ device and the sensor package.

\subsection{Sensor Fabrication}

Spin-coated $\mathrm{NiO}$ was deposited using a photolithography-assisted technique to create two thicknesses of device (S-5 and S-10). NiO (99.99\% trace metal basis) material was purchased from Sigma Aldrich Ltd. and used without further treatment. Spin coating was used over more traditional screen printing as the accuracy of the process is higher. The 
spin-coating ink was prepared by mixing the $\mathrm{NiO}$ with Dirasol-916 (negative photoresist, purchased from Sigma Aldrich, Dorset, UK). A 1:5 weight ratio of $\mathrm{NiO}$ and photoresist was used to which $10 \mathrm{~mL}$ of de-ionized (DI) water was added to get a smooth and consistent ink. Then the substrates were washed with acetone, isopropyl alcohol (IPA), and DI water and were subjected to pre-baking for $2 \mathrm{~min}$ at $60^{\circ} \mathrm{C}$. The prepared ink was poured onto the alumina substrates and spun at 3000 RPM for $30 \mathrm{~s}$ to achieve a homogenous layer. Then the substrate was exposed to UV for $2 \mathrm{~min}$. DI water was used as the developer. Then the substrates were post-baked at $60^{\circ} \mathrm{C}$ for $2 \mathrm{~min}$. The whole process was repeated multiple times to increase the thickness of the sensing material. After this, both types of sensors underwent firing at $800^{\circ} \mathrm{C}$ for an hour at a ramping rate of $5{ }^{\circ} \mathrm{C}$ per min [23].

\subsection{Material Characterisation}

The XRD analysis of all the devices was carried out using a Bruker D8 DISCOVER thin-film PXRD, which is equipped with an un-monochromatic $\mathrm{Cu}$ source and a Ni filter. The data were taken at diffraction angles between $5^{\circ}$ and $95^{\circ}$. The phase identification was made using the Panalytical HighScore Plus V4.8 software and the latest ICDD database. The surface morphology of the fabricated sensors was carried by scanning electron microscopy (SEM) from $5 \mathrm{kV}$ to $10 \mathrm{kV}$.

\subsection{Gas Testing}

As we wished to develop sensors for environmental monitoring, the sensors were evaluated at concentrations that were far below the recommended maximum exposure limits (typically a few hundred parts per million (ppm) for each of the environmental VOCs). Sensors were tested on acetone $\left(\mathrm{C}_{3} \mathrm{H}_{6} \mathrm{O}\right)$, ethanol $\left(\mathrm{C}_{2} \mathrm{H}_{5} \mathrm{OH}\right)$, toluene $\left(\mathrm{C}_{7} \mathrm{H}_{8}\right)$, hexane $\left(\mathrm{C}_{6} \mathrm{H}_{14}\right)$, methanol $\left(\mathrm{CH}_{3} \mathrm{OH}\right)$, 2-propanol $\left(\mathrm{C}_{3} \mathrm{H}_{8} \mathrm{O}\right)$, and isobutylene $\left(\mathrm{C}_{4} \mathrm{H}_{8}\right)$ vapours, between 5 and $25 \mathrm{ppm}$. Figure 2 shows the gas-testing process, where VOC headspaces are developed in such a way as to get the desired concentrations. The gas experiments were performed using a gas rig with 2 mass flow controllers (MFCs) capable of supplying both lines at a defined flow rate, simultaneously. Both gas lines were connected to zero air cylinders, each with a total flow rate of up to $500 \mathrm{~mL} / \mathrm{min}$ [5]. A pre-calibrated bottle, filled with pure chemicals, was placed in the line of one of the MFCs. Each of the VOC concentrations was achieved by changing the flow rate of the target gas line (zero air) into the bottle and the dilution flow rate, with the total flow rate, kept constant. To eliminate any background VOCs entering the bottle, the gas lines were passed through molecular sieves $(120 \mathrm{~mL}$, type $5 \mathrm{~A})$ before the gas rig.

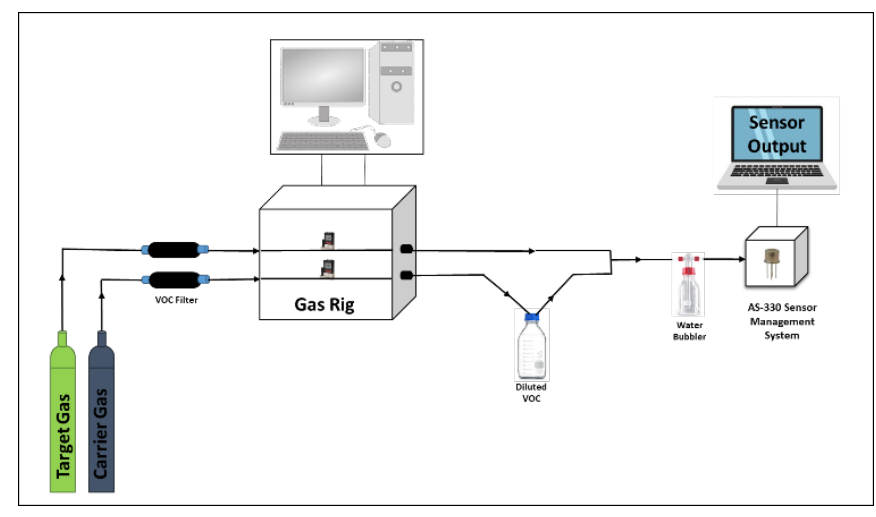

Figure 2. Gas-rig setup.

Humid air was provided by using a water bubbler, where the humidity level was controlled by changing the water level within it and was set to either $40 \%$ or $90 \%$ (error up to $\pm 5 \%$ ) relative humidity (r.h.). The final r.h. values were cross-verified using a commercial humidity sensor (Bosch BME680). As one of the gas lines ran through the pre-calibrated VOC bottle, it was then added to the dilution line, before going on to the water bubbler 
and sensor chamber. The sensors were connected to an AS-330 Sensor Management System (Atmospheric Sensors Ltd., Great Notley, UK). This unit allows accurate control of the sensor temperature and records both heater and sensor resistance. The achieved final VOC gas concentrations were calibrated using a commercial photo-ionization detector (PID) from ION Science (Tiger) after the addition of humidity.

\section{Results}

The detection mechanism of MOX-based gas sensors is chemo-resistive, where a change in the electrical resistance of the sensing material is correlated to the change in gas concentration. Various factors influence the sensing performance including morphology, grain size, active absorption sites, gas diffusion, surface defects, and environmental humidity $[24,25]$. Initially, all sensors were tested at different heater temperatures, ranging from $50{ }^{\circ} \mathrm{C}$ to $400{ }^{\circ} \mathrm{C}$, on isobutylene (dry gas) at concentrations between 2 and $10 \mathrm{ppm}$. For these experiments, there was no addition of humidity, and the measured humidity level was below $10 \%$ r.h. Figure 3 a shows the temperature versus relative response of S-10 and S-5 NiO. The sensors only started to respond from $250{ }^{\circ} \mathrm{C}$ onwards. As can be seen, the magnitude of the response increased as the operating temperature was raised, achieving a maximum at $350{ }^{\circ} \mathrm{C}$. The relative responses $\left(R_{g} / R_{a}-1\right.$, with $R_{g}$ being the resistance in gas and $R_{a}$ being the resistance in zero air), at this temperature towards 10 ppm isobutylene, were 1.2 and 1.0 for S-10 and S-5 thick films, respectively. Figure $3 \mathrm{~b}$ shows the temperature versus response time towards $10 \mathrm{ppm}$ isobutylene, across the measured temperature range. Here, the response time is reduced with increasing operating temperature. The response times of S-5 and S-10 sensors (at $350{ }^{\circ} \mathrm{C}$ ) were $110 \mathrm{~s}$ and $200 \mathrm{~s}$ and less than $80 \mathrm{~s}$ and $120 \mathrm{~s}$, respectively. To the best of our knowledge, there are no $\mathrm{NiO}$ thick-film sensors reported with a faster response time towards VOCs than the S-10 sensor. Since the relative response and response time were better for both types of sensors at $350{ }^{\circ} \mathrm{C}$, the same operating temperature was used for all further sensor testing and comparisons.

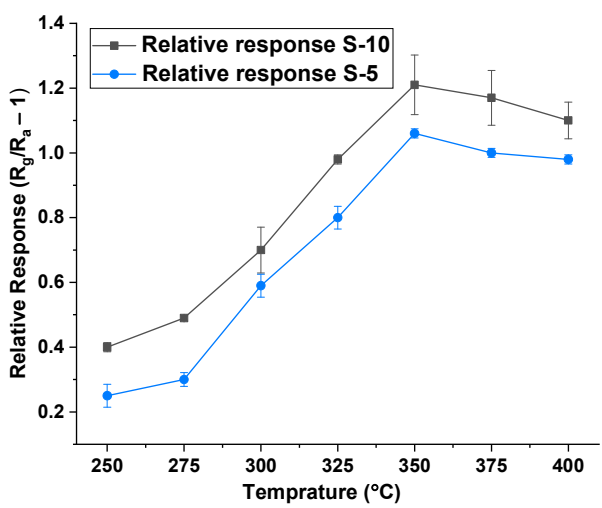

(a)

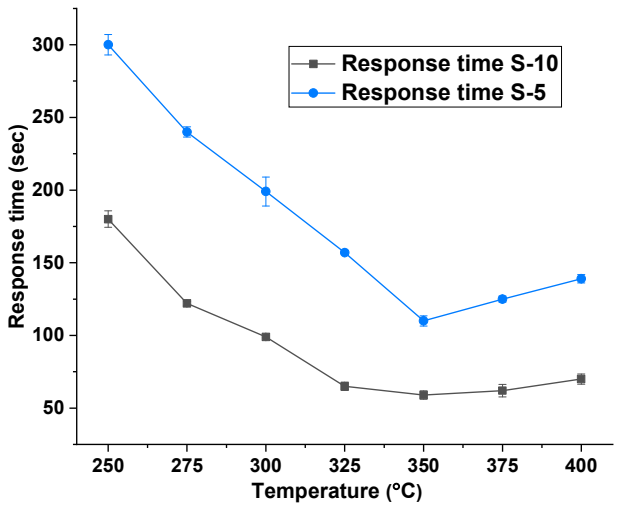

(b)

Figure 3. (a) Temperature vs. relative response of S-10 and S-5 $\mathrm{NiO}$ at $10 \%$ r.h. (b) Temperature vs. response time of $\mathrm{S}-10$ and $\mathrm{S}-5 \mathrm{NiO}$ at $10 \%$ r.h.

The XRD patterns shown in Figure 4 are from an S-10 and S-5 sensor. Both sensors show the formation of $\mathrm{NiO}$ with a rhombohedral structure. The XRD stick pattern of a standard $\mathrm{NiO}$ material was added at the bottom for reference. When compared with the standard pattern, the as-deposited $\mathrm{NiO}$ peaks shifted to a lower 2-theta angle indicating stress in their crystal structure. The deposited $\mathrm{NiO}$ films can be correlated to the ICDD file number 04-011-2340 with a space group: R-3m and cell parameters of a $(\AA): 2.9549, \mathrm{~b}(\AA)$ : 2.9549, and c ( $\AA$ ): 7.2320, as previously observed [26]. There were other peaks observed from alumina substrate $(*)$, gold electrodes $\left({ }^{\#}\right)$, and platinum heaters $(\hat{)})$ as indicated. 


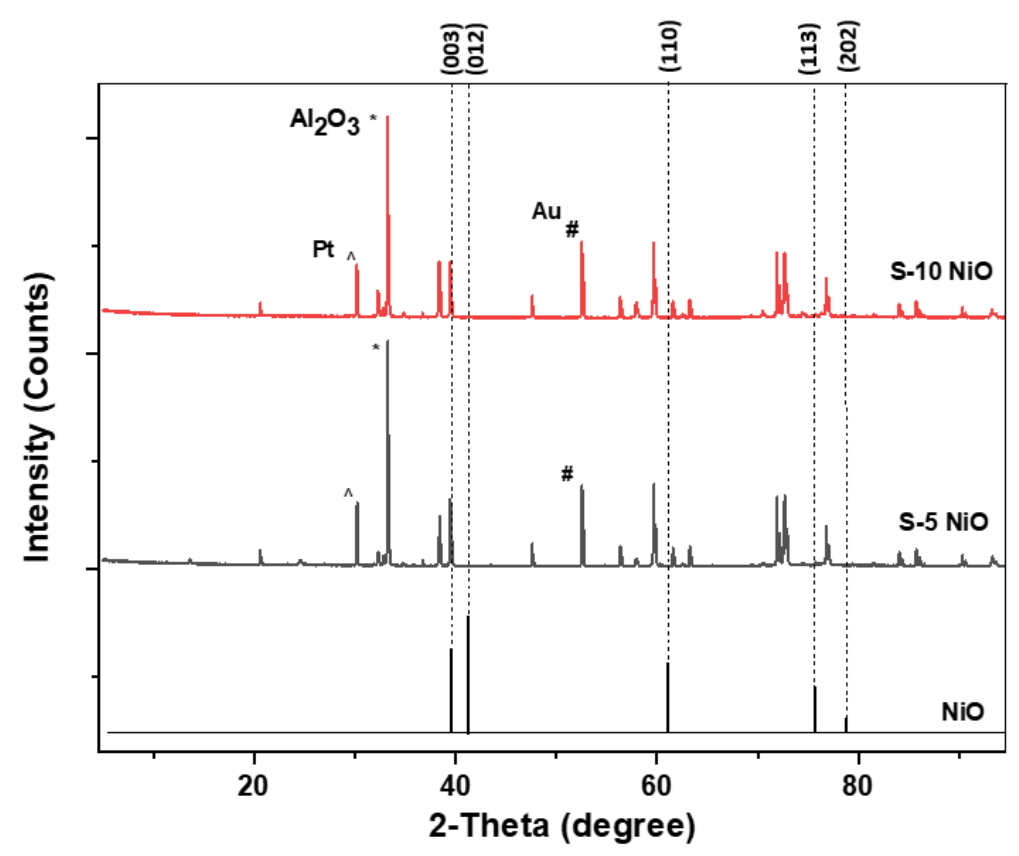

Figure 4. XRD pattern of the deposited S-10 NiO, S-5 NiO, and stick pattern of standard NiO.

SEM cross-section images in Figure $5 b$,d suggest that the film thicknesses are around $5 \mu \mathrm{m}$ and $10 \mu \mathrm{m}$ for S-5 and S-10 NiO sensors, respectively. The SEM images in Figure 5a,c show that the S-10 NiO film has macro-pores, whilst the S-5 NiO film is more compacted. Here, the grains agglomerated into small nanoclusters interconnected through their grain boundaries. In the S-10 sensor, a more open microstructure was observed, which results in a higher surface-to-volume ratio, leading to a higher number of active sites for the solid-gas interaction. Furthermore, the presence of macro-pores in the S-10 sensor allows the target gases to further penetrate through the thickness of the film to interact with the inner grains of the sensing element.

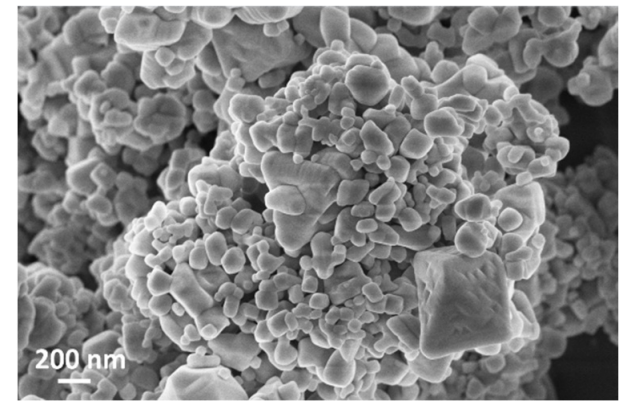

(a)

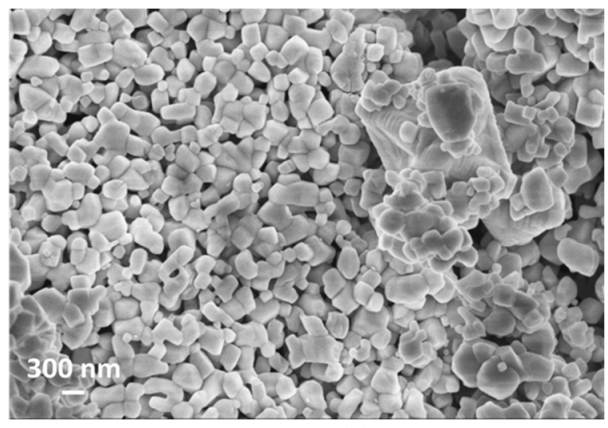

(c)

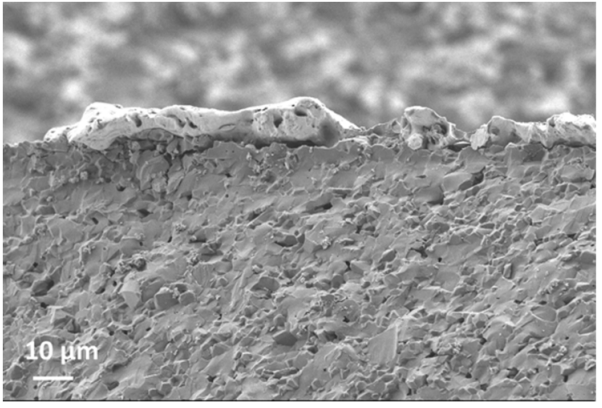

(b)

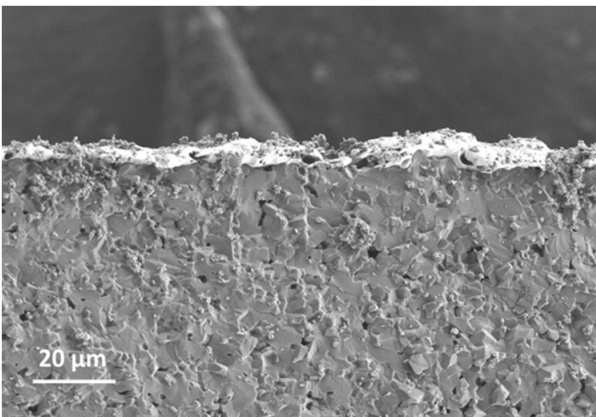

(d)

Figure 5. (a) Surface topography of S-10 NiO. (b) Cross section of S-10 NiO device. (c) Surface topography of S-5 NiO. (d) Cross section of S-5 $\mathrm{NiO}$ device. 
Both types of sensors were tested on acetone, ethanol, 2-propanol, hexane, isobutylene, methanol, and toluene between $5 \mathrm{ppm}$ and $25 \mathrm{ppm}$ in $5 \mathrm{ppm}$ steps at $40 \%$ r.h. condition (using the water bubbler). NiO showed a larger response to ethanol, acetone, methanol, and 2-propanol vapours. Thus, the response was higher for hydroxyl (-OH) and carbonyl functional groups over other groups for the given concentrations. The gas-sensing mechanism could be explained through band bending. When the target gas is introduced, the VOC gas molecules interact with the pre-adsorbed oxygen ions present on the surface and release free electrons. The released electrons neutralize the excess holes present in the $p$-type material ( $\mathrm{NiO}$ in this case) due to charge carrier recombination, which leads to band bending [27]. Figure 6a illustrates the stable response of the S-5 sensor towards all the 7 VOCs at concentrations between $5 \mathrm{ppm}$ and $25 \mathrm{ppm}$ at $350{ }^{\circ} \mathrm{C}$ and $40 \%$ r.h. NiO, being a $p$-type semiconductor material, showed an increase in resistance when subjected to all the VOCs (which in our case are all reducing gases). Similar behaviour was also found for the S-10 sensor, but data are not shown here. Figure 6b-e shows a comparison of concentrations versus relative response of both sensors to four target VOCs. The dotted line represents a linear fit, with standard deviation added for repeated testing.

The relative response $\left(\mathrm{R}_{\mathrm{g}} / \mathrm{R}_{\mathrm{a}}\right)$ of S-10 and S-5 sensors, towards their respective target VOCs for $5 \mathrm{ppm}$, is given in Table 1 . The response behaviours represented here were found to be repeatable indicating the sensors are stable. The stability and reproducibility of these $\mathrm{NiO}$ thick films could be attributed to annealing at high temperatures $\left(800{ }^{\circ} \mathrm{C}\right)$ in the post-processing treatment [28]. Although S-5 and S-10 sensors are fundamentally the same, S-5 showed an overall lower response compared to the other film towards all the VOCs. This could be due to the bigger particle size present in the S- 5 sensor, leading to smaller grain boundaries for gas molecule interaction.

Table 1. Gas relative responses for $\mathrm{NiO}$ towards each $\mathrm{VOC}$ at $5 \mathrm{ppm}$ and $350{ }^{\circ} \mathrm{C}$ at $40 \%$ r.h.

\begin{tabular}{ccc}
\hline VOC Gas & $\begin{array}{c}\mathbf{S}-\mathbf{1 0} \mathbf{N i O} \\
\left(\mathbf{R}_{\mathbf{g}} / \mathbf{R}_{\mathbf{a}}\right)\end{array}$ & $\begin{array}{c}\mathbf{S}-\mathbf{5} \mathbf{N i O} \\
\left(\mathbf{R}_{\mathbf{g}} / \mathbf{R}_{\mathbf{a}}\right)\end{array}$ \\
\hline Acetone & 1.22 & 1.09 \\
Ethanol & 1.27 & 1.13 \\
2-Propanol & 1.21 & 1.12 \\
Toluene & 1.15 & 1.11 \\
Hexane & 1.10 & 1.10 \\
Methanol & 1.22 & 1.12 \\
Isobutylene & 1.03 & 1.02 \\
\hline
\end{tabular}

Humidity affects the sensor performance by changing the baseline resistance, which further affects its sensitivity and response time. The water molecules present in the environment tend to occupy more active sites and reduce the rate of target gas reaction on the surface, making it difficult to detect the target gas, especially at lower concentrations [29]. Therefore, to evaluate the stability of our sensors, we undertook further experiments at different humidity levels. Using a water bubbler, we generated two humidity levels, $40 \%$ r.h. and $90 \%$ r.h. The sensors were tested on isobutylene between $2 \mathrm{ppm}$ and $10 \mathrm{ppm}$ to measure the effect of humidity on the baseline and the sensor response. Figure $7 \mathrm{a}, \mathrm{b}$ show the baseline resistance at $40 \%$ r.h. and $90 \%$ r.h. and the sensor response to isobutylene gas. When comparing the baseline in air between the two devices, there was a $300 \%$ difference in baseline resistance for the S- 5 sensor between the two humidity conditions, while this change was only 3\% in the S-10 sensor. This change of baseline occurs due to additional water molecules interacting with the adsorbed oxygen ions on the active sites of the sensing surface, through hydrogen ions $(\mathrm{H}+)$ and hydroxyl ions $(\mathrm{OH}-)[30,31]$. This is particularly critical when detecting VOCs (reducing gas), as the water molecules interact with the MOX material and release the captured electrons [32]. As a result, the baseline resistance decreases with increasing humidity; therefore, we see the baseline resistance of both sensors at $90 \%$ r.h. to be lower than that at $40 \%$ r.h. However, this phenomenon is 
significantly absent in the S-10 sensor. Figure 7c,d show the relative response between two humidity conditions of S-10 and S- 5 sensors. There was a minimal effect of humidity on the magnitude of response. Furthermore, the baseline was stable for the S-10 sensor, shown by its minimal change in sensitivity and response time towards isobutylene between the humidity conditions. This indicates that S-10 sensors are more humidity-tolerant compared to both S- 5 and $n$-type sensors.

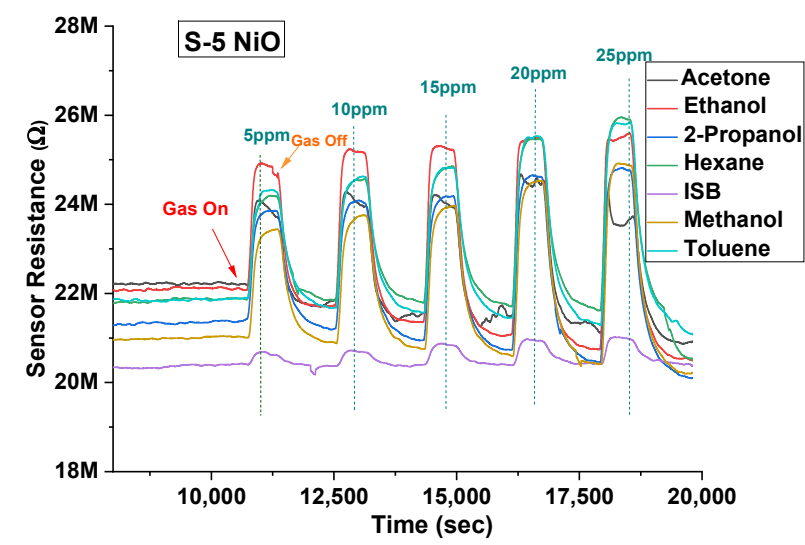

(a)

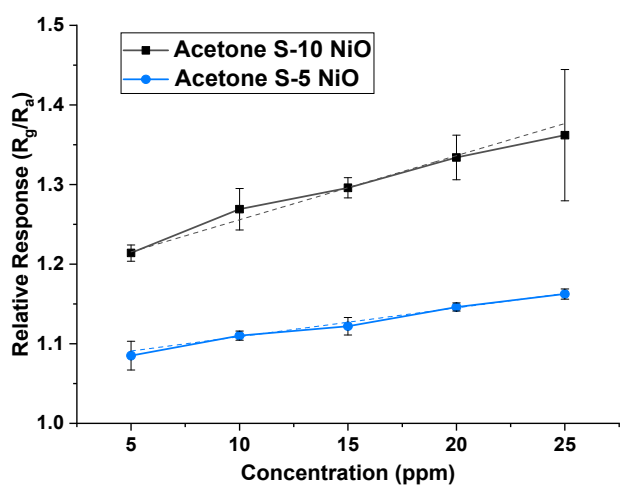

(b)

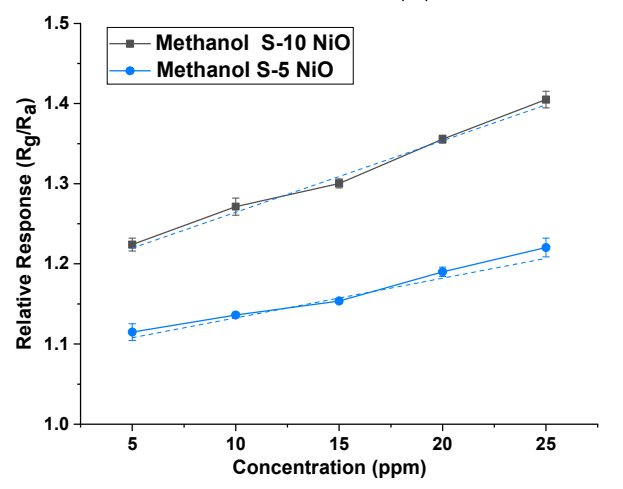

(d)

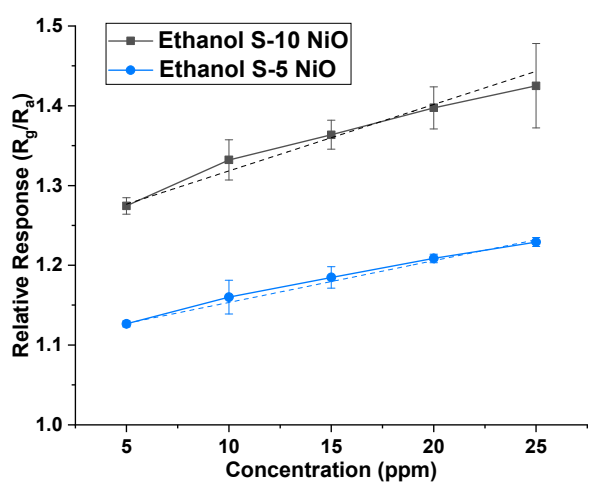

(c)

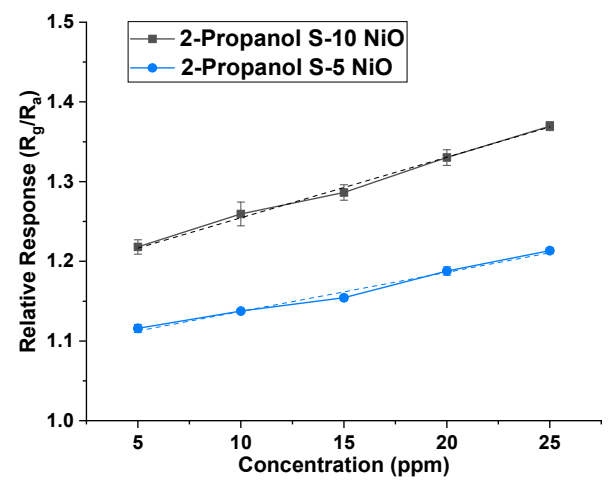

(e)

Figure 6. (a) Sensor response profile of $\mathrm{S}-5 \mathrm{NiO}$ towards all the VOCs at $350{ }^{\circ} \mathrm{C}$ at $40 \%$ r.h. Concentration versus sensitivity of S-5 and S-10 sensors at 40\% r.h. of: (b) acetone; (c) ethanol; (d) methanol; (e) 2-propanol.

Finally, we compared the results of our study with many other thick-film sensors (both $n$-and $p$-type), and this is shown in Table 2. This shows that our films have a lower operating temperature and better sensitivity than several previously reported works. 


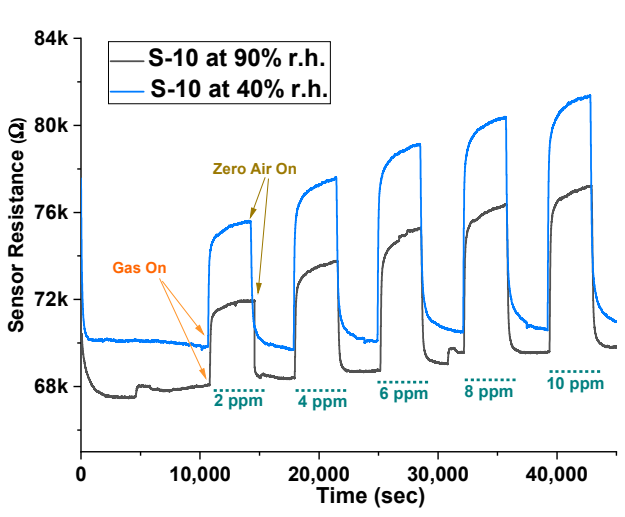

(a)

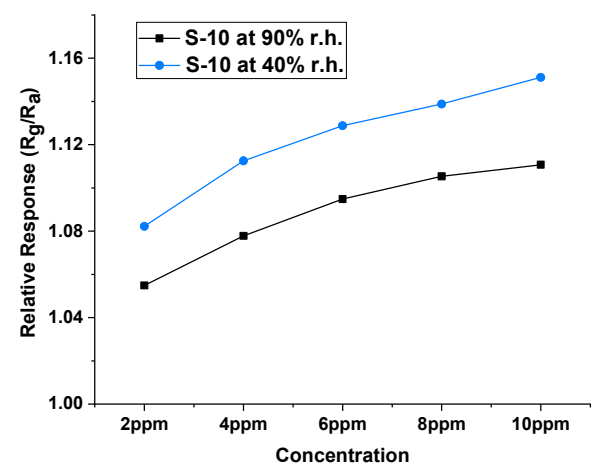

(c)

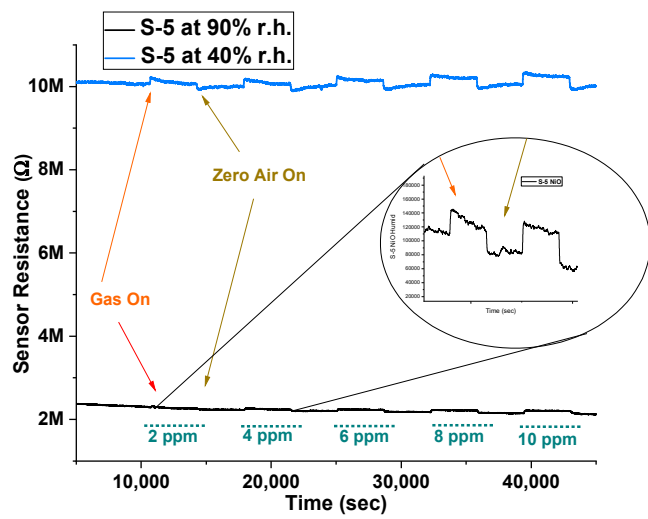

(b)

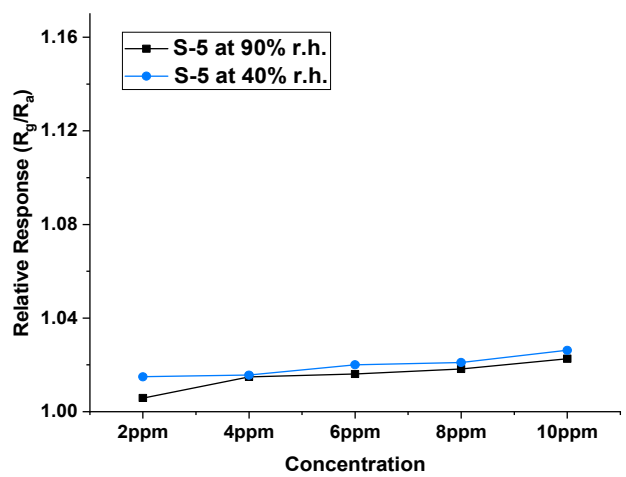

(d)

Figure 7. Baseline resistance and sensor response at 40\% r.h. and at $90 \%$ r.h. conditions of (a) S-10 sensor and (b) S-5 sensor. Relative response $\left(R_{g} / R_{a}\right)$ at $40 \%$ r.h. and at $90 \%$ r.h. conditions of (c) S-10 sensor and (d) S-5 sensor.

Table 2. Comparison table of MOX devices for VOCs versus this work.

\begin{tabular}{|c|c|c|c|c|c|c|c|}
\hline VOC Gas & Target VOCs & ppm Range & Method & Thickness & $\begin{array}{l}\text { Operating } \\
\text { Temperature }\end{array}$ & Response & Reference \\
\hline $\mathrm{ZnO}$ & $\begin{array}{c}\text { Acetone isopropanol } \\
\text { Ethanol }\end{array}$ & $<1000$ ppm & RF sputtering & - & $400^{\circ} \mathrm{C}$ & - & {$[10]$} \\
\hline $\mathrm{WO}_{3}$ thick film & Aromatic hydrocarbons & $0.1-500 \mathrm{ppm}$ & Sputtering & $35 \mu \mathrm{m}$ & $400^{\circ} \mathrm{C}$ & - & {$[11]$} \\
\hline $\begin{array}{l}\text { Doped } \mathrm{ZnO} \\
\text { thick film }\end{array}$ & $\begin{array}{l}\text { Benzene, } \\
\text { Toluene, } \\
\text { Xylene }\end{array}$ & 100 ppm & HILH & & $420^{\circ} \mathrm{C}$ & 2.9 & [12] \\
\hline $\mathrm{SnO}_{2}$ thick film & Formaldehyde & $>10 \mathrm{ppm}$ & Sputtering & $10 \mu \mathrm{m}$ & $266^{\circ} \mathrm{C}$ & - & [13] \\
\hline $\mathrm{ZnO}$ thick film & $\begin{array}{l}\text { Acetone, } \\
\text { Alcohol, } \\
\text { Xylene, } \\
\text { Toluene, } \\
\text { Benzene }\end{array}$ & 100 ppm & $\begin{array}{l}\text { Vapour-phase } \\
\text { oxidation }\end{array}$ & - & $420^{\circ} \mathrm{C}$ & $0.02-0.04$ & [14] \\
\hline Doped $\mathrm{NiO}$ & $\begin{array}{c}\text { Formaldehyde, } \\
\text { Methanol, } \\
\text { Formalin }\end{array}$ & 25-100 ppm & $\begin{array}{l}\text { Wet chemical } \\
\text { method }\end{array}$ & $500 \mathrm{~nm}$ & $600^{\circ} \mathrm{C}$ & - & [21] \\
\hline $\mathrm{NiO}$ thick films & $\begin{array}{c}\text { Acetone, } \\
\text { Ethanol, } \\
\text { Toluene, } \\
\text { Hexane, } \\
\text { Methanol, } \\
\text { Isobutylene, } \\
\text { 2-propanol }\end{array}$ & $<25$ ppm & Spin coating & $\begin{array}{c}5 \mu \mathrm{m} \text { and } \\
10 \mu \mathrm{m}\end{array}$ & $350{ }^{\circ} \mathrm{C}$ & $1.1-1.5$ & This work \\
\hline
\end{tabular}




\section{Conclusions}

Here, we have developed a fast and stable chemo-resistive NiO-based sensor for a wide range of VOCs. We successfully fabricated thick-film NiO (S-5 and S-10) sensors by a photolithography-assisted spin-coated technique. SEM analysis suggests that the thickness of the S- 5 and S-10 sensors was $5 \mu \mathrm{m}$ and $10 \mu \mathrm{m}$, respectively, with the S-10 sensor being more porous. XRD reports indicate a rhombohedral structure with the peaks getting shifted left, suggesting stress in the crystal structure. Both sensors were tested across a temperature range on isobutylene, and it was found that the maximum gas response was at $350{ }^{\circ} \mathrm{C}$. A comparison was made between the sensitivities $\left(R_{\mathrm{g}} / \mathrm{R}_{\mathrm{a}}\right)$ of the two types of $\mathrm{NiO}$ sensors to each of the VOCs. It was found that the S-10 sensor response was relatively high for hydroxyl and carbonyl functional groups, at the tested concentrations, over the other vapours. S-10 and S-5 $\mathrm{NiO}$ sensors were subjected to $40 \%$ r.h. and $90 \%$ r.h., and it was found that the $\mathrm{S}-10 \mathrm{NiO}$ sensors were humidity-tolerant with just a 3\% baseline drift, making it a potential sensor for VOC monitoring. Therefore, we present a humidity-tolerant $\mathrm{NiO}$ thick-film-based VOC sensor.

Author Contributions: J.A.C. conceptualized the project. J.A.C. and S.K.A. designed and fabricated the device. Gas testing, material characterization, and data analysis were carried out by S.K.A. Original draft preparation, review, and editing of the manuscript were completed by S.K.A. and J.A.C. All authors have read and agreed to the published version of the manuscript.

Funding: This research received no external funding.

Data Availability Statement: Not applicable.

Conflicts of Interest: The authors declare no conflict of interest.

\section{References}

1. Rajabi, H.; Mosleh, P.; Mandal, P.; Lea-Langton, A.; Sedighi, M. Emissions of volatile organic compounds from crude oil processing-Global emission inventory and environmental release. Sci. Total Environ. 2020, 727, 138654. [CrossRef]

2. Korotcenkov, G. Handbook of Gas Sensor Materials; Springer Nature: Cham, Switzerland, 2014; Volume 1, ISBN 978-1-4614-7387-9.

3. Kumar, P.; Deep, A.; Kim, K.H.; Brown, R.J.C. Coordination polymers: Opportunities and challenges for monitoring volatile organic compounds. Prog. Polym. Sci. 2015, 45, 102-118. [CrossRef]

4. Balouria, V.; Kumar, A.; Samanta, S.; Singh, A.; Debnath, A.K.; Mahajan, A.; Bedi, R.K.; Aswal, D.K.; Gupta, S.K. Nano-crystalline Fe2O3 thin films for ppm level detection of H2S. Sens. Actuators B Chem. 2013, 181, 471-478. [CrossRef]

5. Mabrook, M.; Hawkins, P. A rapidly-responding sensor for benzene, methanol and ethanol vapours based on films of titanium dioxide dispersed in a polymer operating at room temperature. Sens. Actuators B Chem. 2001, 75, 197-202. [CrossRef]

6. Choi, U.S.; Sakai, G.; Shimanoe, K.; Yamazoe, N. Sensing properties of $\mathrm{SnO}_{2}-\mathrm{Co}_{3} \mathrm{O}_{4}$ composites to CO and $\mathrm{H}_{2}$. Sens. Actuators B Chem. 2004, 98, 166-173. [CrossRef]

7. Becker, T.; Ahlers, S.; Bosch-v.Braunmühl, C.; Müller, G.; Kiesewetter, O. Gas sensing properties of thin- and thick-film tin-oxide materials. Sens. Actuators B Chem. 2001, 77, 55-61. [CrossRef]

8. Bhowmick, T.; Ambardekar, V.; Ghosh, A.; Dewan, M.; Pratim Bandyopadhyay, P.; Nag, S.; Basu Majumder, S. Multilayered and Chemiresistive Thin and Thick Film Gas Sensors for Air Quality Monitoring. Multilayer Thin Film. Versatile Appl. Mater. Eng. 2020, 1-46. [CrossRef]

9. Arshak, K.; Gaidan, I. Development of a novel gas sensor based on oxide thick films. Mater. Sci. Eng. B Solid-State Mater. Adv. Technol. 2005, 118, 44-49. [CrossRef]

10. Al-Hardan, N.H.; Abdullah, M.J.; Abdul Aziz, A.; Ahmad, H.; Low, L.Y. ZnO thin films for VOC sensing applications. Vacuum 2010, 85, 101-106. [CrossRef]

11. Kanda, K.; Maekawa, T. Development of a WO3 thick-film-based sensor for the detection of VOC. Sens. Actuators B Chem. 2005, 108, 97-101. [CrossRef]

12. Zhu, B.L.; Xie, C.S.; Wu, J.; Zeng, D.W.; Wang, A.H.; Zhao, X.Z. Influence of Sb, in and Bi dopants on the response of ZnO thick films to VOCs. Mater. Chem. Phys. 2006, 96, 459-465. [CrossRef]

13. Iizuka, K.; Kambara, M.; Yoshida, T. Growth of tin oxide thick films by plasma spray physical vapor deposition. Sens. Actuators $B$ Chem. 2011, 155, 551-556. [CrossRef]

14. Zhu, B.L.; Xie, C.S.; Wang, A.H.; Zeng, D.W.; Song, W.L.; Zhao, X.Z. The gas-sensing properties of thick film based on tetrapodshaped ZnO nanopowders. Mater. Lett. 2005, 59, 1004-1007. [CrossRef]

15. James, F.; Fiorido, T.; Bendahan, M.; Aguir, K. Comparison between MOX sensors for low VOCs concentrations with interfering gases. In Proceedings of the All Sensors, Nice, France, 19-23 March 2017; pp. 39-40. 
16. Cho, B.; Lee, K.; Pyo, S.; Kim, J. Fabrication and characterization of VOC sensor array based on SnO2 and ZnO nanoparticles functionalized by metalloporphyrins. Micro Nano Syst. Lett. 2018, 6, 10. [CrossRef]

17. Xia, S.; Zhu, H.; Cai, H.; Zhang, J.; Yu, J.; Tang, Z. Hydrothermally synthesized CuO based volatile organic compound gas sensor. RSC Adv. 2014, 4, 57975-57982. [CrossRef]

18. Sari, W.; Smith, P.; Leigh, S.; Covington, J. Oxygen Sensors Based on Screen Printed Platinum and Palladium Doped Indium Oxides. Proceedings 2017, 1, 401. [CrossRef]

19. Kaur, N.; Zappa, D.; Ferroni, M.; Poli, N.; Campanini, M.; Negrea, R.; Comini, E. Branch-like NiO/ZnO heterostructures for VOC sensing. Sens. Actuators B Chem. 2018, 262, 477-485. [CrossRef]

20. Vincent, T.A.; Xing, Y.; Cole, M.; Gardner, J.W. Investigation of the response of high-bandwidth MOX sensors to gas plumes for application on a mobile robot in hazardous environments. Sens. Actuators B Chem. 2019, 279, 351-360. [CrossRef]

21. Dirksen, J.A.; Duval, K.; Ring, T.A. NiO thin-film formaldehyde gas sensor. Sens. Actuators B Chem. 2001, 80, 106-115. [CrossRef]

22. Liu, H.; He, Y.; Nagashima, K.; Meng, G.; Dai, T.; Tong, B.; Deng, Z.; Wang, S.; Zhu, N.; Yanagida, T.; et al. Discrimination of VOCs molecules via extracting concealed features from a temperature-modulated p-type NiO sensor. Sens. Actuators B Chem. 2019, 293, 342-349. [CrossRef]

23. Ayyala, S.K.; Tsang, J.H.; Blackman, C.; Covington, J.A. Comparative study of spin-coated and vapour deposited nickel oxides for detecting VOCs. Proc. IEEE Sens. 2020, 4-7. [CrossRef]

24. Mirzaei, A.; Leonardi, S.G.; Neri, G. Detection of hazardous volatile organic compounds (VOCs) by metal oxide nanostructuresbased gas sensors: A review. Ceram. Int. 2016, 42, 15119-15141. [CrossRef]

25. Lin, T.; Lv, X.; Hu, Z.; Xu, A.; Feng, C. Semiconductor Metal Oxides as Chemoresistive Sensors for Detecting Volatile Organic Compounds. Sensors 2019, 19, 233. [CrossRef] [PubMed]

26. Rodic, D.; Spasojevic, V.; Kusigerski, V.; Tellgren, R.; Rundlof, H. Magnetic ordering in polycrystalline NixZn1-xO Solid Solutions. Phys. Status Solidi Basic Res. 2000, 218, 527-536. [CrossRef]

27. Nguyen, H.; El-Safty, S.A. Meso- and macroporous $\mathrm{Co}_{3} \mathrm{O}_{4}$ nanorods for effective VOC gas sensors. J. Phys. Chem. C 2011, 115, 8466-8474. [CrossRef]

28. Dey, A. Semiconductor metal oxide gas sensors: A review. Mater. Sci. Eng. B Solid-State Mater. Adv. Technol. 2018, 229, 206-217. [CrossRef]

29. Mahdavi, H.; Rahbarpour, S.; Hosseini-Golgoo, S.M.; Jamaati, H. Reducing the destructive effect of ambient humidity variations on gas detection capability of a temperature modulated gas sensor by calcium chloride. Sens. Actuators B Chem. 2020, $331,129091$. [CrossRef]

30. Faia, P.M.; Furtado, C.S. Effect of composition on electrical response to humidity of $\mathrm{TiO}_{2}: \mathrm{ZnO}$ sensors investigated by impedance spectroscopy. Sens. Actuators B Chem. 2013, 181, 720-729. [CrossRef]

31. Hübner, M.; Simion, C.E.; Tomescu-Stănoiu, A.; Pokhrel, S.; Bârsan, N.; Weimar, U. Influence of humidity on CO sensing with p-type $\mathrm{CuO}$ thick film gas sensors. Sens. Actuators B Chem. 2011, 153, 347-353. [CrossRef]

32. Saruhan, B.; Lontio Fomekong, R.; Nahirniak, S. Review: Influences of Semiconductor Metal Oxide Properties on Gas Sensing Characteristics. Front. Sens. 2021, 2, 657931. [CrossRef] 